\title{
Promoter-specific control of E. coli RNA polymerase by ppGpp and a general transcription factor
}

\author{
Jeffrey W. Roberts ${ }^{1}$ \\ Department of Molecular Biology and Genetics, Cornell University, Ithaca, New York 14853, USA
}

The stringent response of Escherichia coli reflects a global influence of the nucleotide ppGpp on gene expression in response to nutrient starvation. For critical elements of the response, the target of ppGpp is RNA polymerase, which can be either repressed or activated in a promoter-dependent way. A small protein, DksA, which binds in the secondary channel of RNA polymerase, possibly along with other general regulatory factors, contributes to ppGpp-dependent transcription regulation. Rutherford and colleagues (pp. 236-248) identify mutations in genes for the core subunits of RNA polymerase that circumvent the need for DksA in the regulation; the sites of these mutations suggest that DksA acts allosterically through the RNA polymerase active site to destabilize transcription initiation complexes.

Eubacterial, eukaryotic, and archaeal multisubunit RNA polymerases are highly similar overall, with the greatest conservation of molecular structure and enzymatic function found in the active site and the nucleic acid-binding portions of the active site channel (Darst 2001). Understanding regulatory mechanisms that affect these elements of the bacterial enzyme should therefore provide universal insights into modes of transcription regulation. One such regulatory pathway of bacteria that targets RNA polymerase directly, rather than acting through specific transcription factor DNA-binding sites, is thought to derive its specificity from the properties of the core promoter elements themselves. In the "stringent" response (Cashel et al. 1996; Paul et al. 2004b; Potrykus and Cashel 2008; Srivatsan and Wang 2008), the highly conserved machinery of DNA entry into the active site and catalysis of RNA chain synthesis are believed to be a target of a starvation signal that is widespread in bacteria: the nucleotides ppGpp and pppGpp (hereafter just "ppGpp"), long merrily called the "magic spot" (Cashel and Gallant 1969). In this issue of Genes \&

[Keywords: RNA polymerase; promoter; DksA; ppGpp; transcription initiation; ribosome synthesis]

${ }^{1}$ Correspondence.

E-MAIL jwr7@cornell.edu; FAX (607) 255-2428.

Article is online at http://www.genesdev.org/cgi/doi/10.1101/gad.1770509.
Development, Rutherford et al. (2009) provide new insights into this signaling pathway and show how basic elements of the RNA polymerase active center can be targeted by regulatory molecules.

The stringent response mediated by ppGpp in Escherichia coli is a widespread reorientation of gene expression upon depletion of an amino acid (Durfee et al. 2008; Traxler et al. 2008); it is part of a general response to shortage of various nutrients, including amino acids, carbon source, phosphorus, and fatty acids, which also is responsible for subtle modifications of cell growth rate in response to different nutrient availability. The signaling agent ppGpp is made by the enzymes RelA and SpoT in E. coli (Potrykus and Cashel 2008); for the stringent response resulting from amino acid starvation, the ribosome-associated RelA detects an uncharged tRNA bound to the ribosome and catalyzes massive conversion of cellular GTP to ppGpp (Haseltine et al. 1972). This nucleotide then turns down expression of operons for ribosomal and transfer RNA synthesis and, contrarily, stimulates expression of other operons, especially those involved in amino acid biosynthesis (Cashel et al. 1996; Paul et al. 2004b; Haugen et al. 2008). Although the overall stringent response is complex and involves other targets and ultimately hundreds of genes, the stringent control of these two sets of target promoters is of particular interest because, at least for these, the control involves direct modulation of RNA polymerase activity.

\section{Promoter-specific effects of ppGpp and DksA}

The ability of ppGpp to inactivate ribosomal RNA operons specifically is thought to derive from the distinctive property of their promoters to have a very unstable open complex, the terminal stage of promoter activation that poises the template DNA strand in the active site and enables RNA chain polymerization and establishment of the active RNA chain elongation complex (Zhou and Jin 1997, 1998; Barker et al. 2001b; Paul et al. 2004a). Richard Gourse's laboratory (Barker et al. 2001b) has shown that although ribosomal RNA promoters support a very high rate of initiation and promoter clearance-giving rise to nearly close-packed transcription complexes at their best- the open complex is so unstable that any further 
destabilization efficiently inactivates the promoters. This destabilization is an activity of ppGpp, although ppGpp alone is not sufficient; the cellular transcription factor DksA acts along with ppGpp to provide sufficient destabilization (Paul et al. 2004a). Together, ppGpp and DksA reproduce ribosomal RNA promoter inactivation in a purified transcription system. The specificity for stable RNA operon promoters is thought to derive from the fact that open complexes of other promoters have enough inherent stability to make the quantitative effect of ppGpp and DksA irrelevant, resulting in specific targeting of stable RNA operons (Paul et al. 2004a; Haugen et al. 2008).

How, then, could ppGpp activate other promoters? Both in vivo and in vitro evidence is strong that the same pair of factors, ppGpp and DksA, is responsible. An early model ascribed activation to an indirect effect of inhibiting ribosomal promoters, namely, an increase in the concentration of free RNA polymerase, which would stimulate promoters whose activation is limited at the step of initial RNA polymerase binding (Zhou and Jin 1997, 1998; Barker et al. 2001a), and perhaps favor the activity of alternate $\sigma$ factors (Jishage et al. 2002; Costanzo et al. 2008). This effect is likely to be important among the large collection of regulatory changes of the stringent response. However, ppGpp and DksA also directly activate some promoters, especially those for amino acid biosynthetic operons (Paul et al. 2005). The conjecture is that ppGpp/DksA binding reduces the activation energy for the transition from the initial (closed) promoter-RNA polymerase complex and thus increases the rate of formation of the open complex by removing a kinetic barrier (Paul et al. 2005); it is not clear how this can be precisely the same kinetic change that also destabilizes ribosomal promoters, but then further analysis like the current experiments should help to clarify the question.

\section{DksA is a cofactor of ppGpp in transcription regulation}

DksA is one of an important class of proteins that modulate activities of the catalytic center of RNA polymerase by binding in the secondary channel-a portal that is separate from the larger groove where DNA enters and that is thought particularly to affect the catalytic production of RNA (Paul et al. 2004a; Perederina et al. 2004). The secondary channel serves both as the entry point for the nucleoside triphosphate precursors and the exit point for RNA that is extruded in the "backtracking" reaction, a response to certain disruptions of RNA synthesis that are not entirely understood. The best characterized RNA polymerase accessory proteins that bind in the secondary channel act on backtracked RNA, mediating its cleavage and restoring a transcription complex ready to resume RNA synthesis: These are the bacterial Gre proteins, along with their functional eukaryotic counterpart TFIIS, which contain a finger that projects into the active center through the secondary channel (Nickels and Hochschild 2004). Their mode of action is to position a $\mathrm{Mg}^{2+}$ ion bound to carboxylates at the end of the finger in the catalytic center, completing the $\mathrm{Mg}^{2+}$ catalytic pair that is required for the active center to hydrolyze off the protruding RNA; such hydrolysis is one of a series of related phospho-transfer reactions that the RNA polymerase active site supports in addition to its basic RNA polymerization activity (Sosunov et al. 2005). An atomic structure of DksA shows that it has a similar although not identical finger to Gre proteins (Perederina et al. 2004) and also contains residues that would chelate $\mathrm{Mg}^{2+}$, although DksA does not mediate the cleavage reaction. Instead, along with ppGpp, DksA appears to modulate the function of the active center to achieve instability of the open promoter complex.

Although the activity of ppGpp and DksA to inhibit or activate promoters is clear, their molecular mechanism is not. First, the natural binding site of ppGpp on E. coli RNA polymerase is not yet known; there are two atomic structures of Thermus thermophilus RNA polymerase with ppGpp bound in different orientations around the active site (Artsimovitch et al. 2004), but, despite the strong conservation of active center residues where ppGpp binds, the authenticity of these structures has been disputed (Vrentas et al. 2008); one problem, for example, is that ppGpp is not a natural regulator in T. thermophilus, the only bacterial species for which crystallographic evidence exists. Second, although there is good evidence that DksA binds around and projects into the secondary channel like Gre proteins, there is no atomic structure of a bound complex, and hence no indication of exactly how the active center might be affected. In fact, there must be some common effect of DksA and Gre binding in the secondary channel, because the variant GreB can replace DksA for stringent regulation in vitro, and both GreB and GreA replace DksA in vivo if they are overexpressed at high concentration (Potrykus et al. 2006; Rutherford et al. 2007).

\section{Genetic analysis of ppGpp and DksA function}

Clearly, a genetic approach to these problems should be fruitful. Since spoT/relA cells that are unable to make ppGpp require amino acids for growth, suppressors that grow without added amino acids (prototrophic cells) can be isolated, and such mutations are found to map exclusively in different subunits of RNA polymerase (Hernandez and Cashel 1995; Bartlett et al. 1998; Trautinger and Lloyd 2002; Murphy and Cashel 2003; Szalewska-Palasz et al. 2007). These mutants have the property of simulating the stringent state; i.e., turning down ribosomal RNA synthesis and activating amino acid biosynthetic operons. The purified altered enzymes also destabilize the open complex of ribosomal RNA promoters in vitroclearly consistent with the model described above for control of stable RNA operons. In a particularly interesting connection between transcription and DNA repair, a similar set of mutations simulates an effect of ppGpp in rescuing cells from DNA damage in certain mutational backgrounds (Trautinger and Lloyd 2002; Trautinger et al. 2005), suggesting that there is an effect of ppGpp and 
DksA on the stability of transcription elongation complexes trapped by DNA damage.

The current study by Rutherford et al. (2009) both significantly extends the genetic analysis and provides a persuasive connection of DksA activity to conformational changes that occur as RNA polymerase accesses the promoter. Rutherford et al. (2009) selected suppressors to prototrophy from $d k s A$ mutants and showed that these map (like most of the suppressors of spoT/relA) in the large $\beta$ and $\beta^{\prime}$ core subunits of RNA polymerase. Some of these are identical to suppressors of spoT/relA mutants and to mutants obtained by more indirect selections (including the DNA repair effects), and they all have the same property of instability of the ribosomal promoter open complex. In fact, all tested suppressors of either deficiency (i.e., ppGpp or DskA) also suppress the other deficiency, consistent with their affecting the same pathway.

A difference, however, is that the $d k s A$ suppressor mutations are concentrated in two important regions of RNA polymerase: the switch regions and the bridge helix. The fact that some switch residues also contact DNA in the open promoter complex could imply that the switch mutations simply weaken DNA contacts required to stabilize the open complex; however, the depth of this collection of mutants suggests a more interesting interpretation. The switch regions are thought to act as hinges for movement of the RNA polymerase clamp, a segment of the main DNA channel that closes on DNA downstream from the templating site in the active center; since formation of the promoter open complex involves clamp closure, switch mutations might impair open complex formation and thus simulate the effect of DksA on complex stability.

Another recent discovery emphasizes the importance of the switch regions: The RNA polymerase inhibitor and antibiotic myxopyronin was shown to bind to the switch regions of $T$. thermophilus RNA polymerase (Belogurov et al. 2008; Mukhopadhyay et al. 2008). Since myxopyronin inhibits promoter function but not elongation of RNA chains, an attractive conjecture is that myxopyronin prevents the opening reaction that is required for DNA to enter the active channel (Belogurov et al. 2008; Mukhopadhyay et al. 2008). The properties of myxopyronin thus provide an independent connection between the switch regions and the formation of open promoter complexes.

\section{Biochemical analysis and mechanistic models of ppGpp/DksA signaling}

Rutherford et al. (2009) also precisely define through footprinting analysis the step of open promoter complex formation that is inhibited by ppGpp/DksA; namely, the transition from a closed complex to an "intermediate" complex, in which DNA is bound firmly in the downstream clamp but not yet melted to expose the template strand, as occurs in the open complex. Agreeably, the mutations that simulate the ppGpp/DksA activity also inhibit this transition, a result that constructs a more precise connection between the regulators and the genetically defined sites.

The occurrence of some $d k s A$ suppressors in the bridge helix suggests how DksA binding in the secondary channel might inhibit clamp closure and fixation of the nucleic acid scaffold in the active center channel. The bridge helix and trigger loop are elements of the active center that are believed to act together in repetitive conformation changes that occur during the translocation cycle and are accessible through the secondary channel (Vassylyev et al. 2007). Rutherford et al. (2009) conjecture that DksA contacts these elements through the secondary channel and that the bridge helix in turn transmits an allosteric signal to the switch regions. As this model would predict, mutational disruption of the trigger loop prevents promoter destabilization by DksA.

Both the molecular details of these interactions and the role of ppGpp remain to be understood. DksA is active alone at high concentrations in vitro in destabilizing ribosomal promoter complexes and activating some amino acid biosynthetic operon complexes, and the biochemical analysis described here involved DksA alone. However DksA exists at a constant and inactive concentration in vivo (Rutherford et al. 2007), and the real signal in vivo is ppGpp, which acts synergistically with DksA; the mode of interaction of ppGpp is yet unresolved. Furthermore, no structural correlate exists of the activation of promoters by ppGpp and DksA, and that reaction remains mysterious. But the detailed mutational analysis reported here is one approach to convert the static images provided by crystallography to a mechanistic view of molecular motions that underlie this pathway of regulation of RNA polymerase activity.

\section{Acknowledgments}

I thank Mike Cashel and members of the laboratory for criticizing the manuscript.

\section{References}

Artsimovitch, I., Patlan, V., Sekine, S., Vassylyeva, M.N., Hosaka, T., Ochi, K., Yokoyama, S., and Vassylyev, D.G. 2004. Structural basis for transcription regulation by alarmone ppGpp. Cell 117: 299-310.

Barker, M.M., Gaal, T., and Gourse, R.L. 2001a. Mechanism of regulation of transcription initiation by ppGpp. II. Models for positive control based on properties of RNAP mutants and competition for RNAP. J. Mol. Biol. 305: 689-702.

Barker, M.M., Gaal, T., Josaitis, C.A., and Gourse, R.L. 2001b. Mechanism of regulation of transcription initiation by ppGpp. I. Effects of ppGpp on transcription initiation in vivo and in vitro. J. Mol. Biol. 305: 673-688.

Bartlett, M.S., Gaal, T., Ross, W., and Gourse, R.L. 1998. RNA polymerase mutants that destabilize RNA polymerase-promoter complexes alter NTP-sensing by rrn P1 promoters. J. Mol. Biol. 279: 331-345.

Belogurov, G.A., Vassylyeva, M.N., Sevostyanova, A., Appleman, J.R., Xiang, A.X., Lira, R., Webber, S.E., Klyuyev, S., Nudler, E., Artsimovitch, I., et al. 2008. Transcription inactivation through local refolding of the RNA polymerase structure. Nature doi:10.1038/nature07510. 
Cashel, M. and Gallant, J. 1969. Two compounds implicated in the function of the RC gene of Escherichia coli. Nature 221: 838-841.

Cashel, M., Gentry, D.R., Hernandez, J.V., and Vinella, D. 1996. Escherichia coli and Salmonella, cellular and molecular biology. In Escherichia coli and Salmonella, cellular and molecular biology (ed. F.C. Neidhardt), pp. 1458-1496. American Society for Microbiology, Washington, DC.

Costanzo, A., Nicoloff, H., Barchinger, S.E., Banta, A.B., Gourse, R.L., and Ades, S.E. 2008. ppGpp and DksA likely regulate the activity of the extracytoplasmic stress factor $\sigma^{\mathrm{E}}$ in Escherichia coli by both direct and indirect mechanisms. Mol. Microbiol. 67: 619-632.

Darst, S.A. 2001. Bacterial RNA polymerase. Curr. Opin. Struct. Biol. 11: 155-162.

Durfee, T., Hansen, A.M., Zhi, H., Blattner, F.R., and Jin, D.J. 2008. Transcription profiling of the stringent response in Escherichia coli. J. Bacteriol. 190: 1084-1096.

Haseltine, W.A., Block, R., Gilbert, W., and Weber, K. 1972. MSI and MSII made on ribosome in idling step of protein synthesis. Nature 238: 381-384.

Haugen, S.P., Ross, W., and Gourse, R.L. 2008. Advances in bacterial promoter recognition and its control by factors that do not bind DNA. Nat. Rev. Microbiol. 6: 507-519.

Hernandez, V.J. and Cashel, M. 1995. Changes in conserved region 3 of Escherichia coli $\sigma^{70}$ mediate ppGpp-dependent functions in vivo. J. Mol. Biol. 252: 536-549.

Jishage, M., Kvint, K., Shingler, V., and Nystrom, T. 2002. Regulation of $\sigma$ factor competition by the alarmone ppGpp. Genes \& Dev. 16: 1260-1270.

Mukhopadhyay, J., Das, K., Ismail, S., Koppstein, D., Jang, M., Hudson, B., Sarafianos, S., Tuske, S., Patel, J., Jansen, R., et al. 2008. The RNA polymerase 'switch region' is a target for inhibitors. Cell 135: 295-307.

Murphy, H. and Cashel, M. 2003. Isolation of RNA polymerase suppressors of a (p)ppGpp deficiency. Methods Enzymol. 371: 596-601.

Nickels, B.E. and Hochschild, A. 2004. Regulation of RNA polymerase through the secondary channel. Cell 118: 281-284.

Paul, B.J., Barker, M.M., Ross, W., Schneider, D.A., Webb, C., Foster, J.W., and Gourse, R.L. 2004a. DksA: A critical component of the transcription initiation machinery that potentiates the regulation of rRNA promoters by ppGpp and the initiating NTP. Cell 118: 311-322.

Paul, B.J., Ross, W., Gaal, T., and Gourse, R.L. 2004b. rRNA transcription in Escherichia coli. Annu. Rev. Genet. 38: 749770

Paul, B.J., Berkmen, M.B., and Gourse, R.L. 2005. DksA potentiates direct activation of amino acid promoters by ppGpp. Proc. Nat1. Acad. Sci. 102: 7823-7828.

Perederina, A., Svetlov, V., Vassylyeva, M.N., Tahirov, T.H., Yokoyama, S., Artsimovitch, I., and Vassylyev, D.G. 2004. Regulation through the secondary channel-structural framework for ppGpp-DksA synergism during transcription. Cell 118: 297-309.

Potrykus, K. and Cashel, M. 2008. (p)ppGpp: Still magical? Annu. Rev. Microbiol. 62: 35-51.

Potrykus, K., Vinella, D., Murphy, H., Szalewska-Palasz, A., D'Ari, R., and Cashel, M. 2006. Antagonistic regulation of Escherichia coli ribosomal RNA rrnB P1 promoter activity by GreA and DksA. J. Biol. Chem. 281: 15238-15248.

Rutherford, S.T., Lemke, J.J., Vrentas, C.E., Gaal, T., Ross, W., and Gourse, R.L. 2007. Effects of DksA, GreA, and GreB on transcription initiation: Insights into the mechanisms of factors that bind in the secondary channel of RNA polymerase. J. Mol. Biol. 366: 1243-1257.
Rutherford, S.T., Villers, C.L., Lee, J.-H., Ross, W., and Gourse, R.L. 2009. Allosteric control of Escherichia coli rRNA promoter complexes by DksA. Genes \& Dev. (this issue). doi:10.1101/ gad.1745409.

Sosunov, V., Zorov, S., Sosunova, E., Nikolaev, A., Zakeyeva, I., Bass, I., Goldfarb, A., Nikiforov, V., Severinov, K., and Mustaev, A. 2005. The involvement of the aspartate triad of the active center in all catalytic activities of multisubunit RNA polymerase. Nucleic Acids Res. 33: 4202-4211.

Srivatsan, A. and Wang, J.D. 2008. Control of bacterial transcription, translation and replication by (p)ppGpp. Curr. Opin. Microbiol. 11: 100-105.

Szalewska-Palasz, A., Johansson, L.U., Bernardo, L.M., Skarfstad, E., Stec, E., Brannstrom, K., and Shingler, V. 2007. Properties of RNA polymerase bypass mutants: Implications for the role of ppGpp and its co-factor DksA in controlling transcription dependent on $\sigma^{54}$. J. Biol. Chem. 282: 1804618056.

Trautinger, B.W. and Lloyd, R.G. 2002. Modulation of DNA repair by mutations flanking the DNA channel through RNA polymerase. EMBO I. 21: 6944-6953.

Trautinger, B.W., Jaktaji, R.P., Rusakova, E., and Lloyd, R.G. 2005. RNA polymerase modulators and DNA repair activities resolve conflicts between DNA replication and transcription. Mol. Cell 19: 247-258.

Traxler, M.F., Summers, S.M., Nguyen, H.T., Zacharia, V.M., Hightower, G.A., Smith, J.T., and Conway, T. 2008. The global, ppGpp-mediated stringent response to amino acid starvation in Escherichia coli. Mol. Microbiol. 68: 11281148.

Vassylyev, D.G., Vassylyeva, M.N., Perederina, A., Tahirov, T.H., and Artsimovitch, I. 2007. Structural basis for transcription elongation by bacterial RNA polymerase. Nature 448: 157162.

Vrentas, C.E., Gaal, T., Berkmen, M.B., Rutherford, S.T., Haugen, S.P., Vassylyev, D.G., Ross, W., and Gourse, R.L. 2008. Still looking for the magic spot: The crystallographically defined binding site for ppGpp on RNA polymerase is unlikely to be responsible for rRNA transcription regulation. J. Mol. Biol. 377: 551-564.

Zhou, Y.N. and Jin, D.J. 1997. RNA polymerase $\beta$ mutations have reduced $\sigma^{70}$ synthesis leading to a hyper-temperature-sensitive phenotype of a $\sigma^{70}$ mutant. J. Bacteriol. 179: 4292-4298.

Zhou, Y.N. and Jin, D.J. 1998. The rpoB mutants destabilizing initiation complexes at stringently controlled promoters behave like 'stringent' RNA polymerases in Escherichia coli. Proc. Natl. Acad. Sci. 95: 2908-2913. 


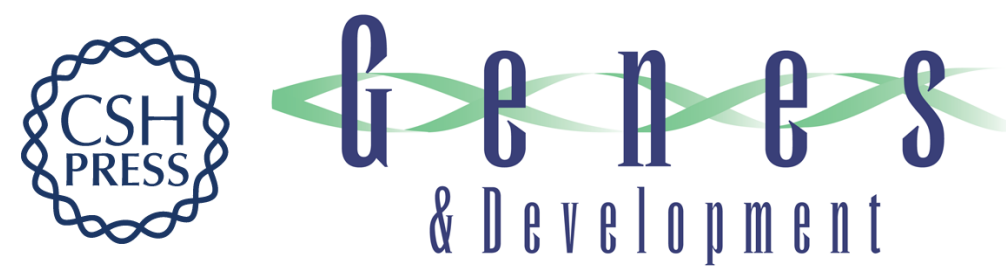

\section{Promoter-specific control of E. coli RNA polymerase by ppGpp and a general transcription factor}

Jeffrey W. Roberts

Genes Dev. 2009, 23:

Access the most recent version at doi:10.1101/gad.1770509
Related Content Allosteric control of Escherichia coli rRNA promoter complexes by DksA Steven T. Rutherford, Courtney L. Villers, Jeong-Hyun Lee, et al.
Genes Dev. January , 2009 23: 236-248
References This article cites 32 articles, 7 of which can be accessed free at: http://genesdev.cshlp.org/content/23/2/143.full.html\#ref-list-1
Articles cited in:
http://genesdev.cshlp.org/content/23/2/143.full.html\#related-urls

\section{License}
Email Alerting
Service
Receive free email alerts when new articles cite this article - sign up in the box at the top right corner of the article or click here.

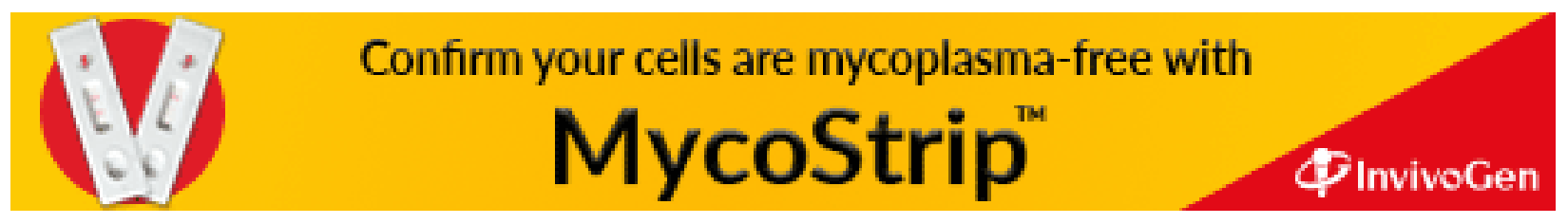

